\title{
Analisis Tingkat Kesadaran Mahasiswa Pendidikan Fisika Semester 2 Terhadap Pengelolaan Sampah Plastik Sekali Pakai
}

\author{
Fitri Amelia ${ }^{1 *}$, Sudarti $^{1}$ \\ ${ }^{1}$ Program Studi Pendidikan Fisika, FKIP Universitas Jember, \\ Banyuwangi 68472, Indonesia \\ *e-mail:190210102106@mail.unej.ac.id
}

Received: 04 Mei 2020. Accepted: 29 Juni 2020. Published: Juli 2020

\begin{abstract}
Abstrak
Keberadaan sampah plastik mengalami peningkatan setiap tahunnya. Hal tersebut dikarenakan masyarakat menghasilkan sampah plastik setiap harinya dan tidak melakukan pengelolaan sampah plastik dengan tepat. Kesadaran masyarakat terhadap pengelolaan sampah plastik masih cukup rendah. Oleh karena itu, penelitian ini bertujuan untuk menganalisis aspek pengetahuan Mahasiswa Pendidikan Fisika Semester 2 Universitas Jember mengenai pengelolaan sampah plastik serta aspek kesadaran tindakan yang telah dilakukan Mahasiswa Pendidikan Fisika Semester 2 Universitas Jember dalam pengelolaan sampah plastik sekali pakai. Penelitian dilakukan dengan menggunakan metode deskriptif melalui instrumen kuisioner pada 100 mahasiswa. Berdasarkan hasil analisis diperoleh bahwa tingkat kesadaran Mahasiswa Pendidikan Fisika Semester 2 Universitas Jember terhadap pengelolaan sampah plastik sekali pakai dilihat dari aspek pengetahuan dan aspek kesadaran tindakan sudah baik. Terbukti dari banyaknya presentase yang diperoleh pada setiap pertanyaan dalam kuisioner, serta hanya 3\% responden yang tidak melakukan upaya 3R dan $6 \%$ responden tidak melakukan upaya diet sampah. Namun hasil analisis tersebut masih sebatas teoritis, sehingga diperlukan tindakan nyata sebagai upaya pengelolaan sampah plastik sekali pakai.
\end{abstract}

Kata Kunci: pengelolaan sampah plastik, plastik sekali pakai, sampah

\section{Analysis of the Level of Awareness of Semester $2^{\text {th }}$ Physics Education Students Against Single-Use Plastic Waste Management}

\begin{abstract}
The existence of plastic waste has increased every year. This is because people produce plastic waste every day and do not manage plastic waste properly. Public awareness of plastic waste management is still quite low. Therefore, this study aims to analyze the knowledge aspects of the 2nd Semester Physics Education Students of the University of Jember regarding the management of plastic waste as well as the awareness aspects of the actions taken by the 2nd Semester Physics Education Students of the University of Jember in the management of single-use plastic waste. The research was conducted using a descriptive method through a questionnaire instrument to 100 students. Based on the results of the analysis, it was found that the level of awareness of the 2nd Semester Physics Education Students of the University of Jember towards disposable waste management seen from the aspect of knowledge and the aspect of awareness of action was good. It is evident from the large percentage obtained for each question in the questionnaire, and only $3 \%$ of respondents did not make the $3 R$ effort and $6 \%$ of respondents did not make an effort to make a waste diet. However, the results of the analysis are still only theoretical, so that real action is needed as an effort to manage single-use plastic waste.
\end{abstract}

Keywords: management of plastic waste, single-use plastics, garbage 


\section{Analisis Tingkat Kesadaran...Jupiter... Vol 2 No 1...Juli 2020...24-31}

Fitri Amelia, Sudarti

\section{PENDAHULUAN}

Fisika lingkungan merupakan salah satu mata kuliah wajib bagi mahasiswa pendidikan fisika Universitas Jember. Fisika lingkungan membahas mengenai berbagai objek fisis yang berkaitan dengan sistem ekologi dan pencemaran lingkungan, serta hubungan antara makhluk hidup dengan lingkungannya. Tujuan dari pembelajaran fisika lingkungan ini agar mahasiswa dapat memahami permasalahan lingkungan yang ada disekitarnya, dapat meminimalisir dan menangani permasalahan lingkungan, serta menumbuhkan kesadaran mahasiswa untuk peduli terhadap lingkungan (Siswadi et al., 2012). Pembelajaran fisika lingkungan berguna untuk memberikan pemahaman kepada mahasiswa mengenai konsep fisika dan cara pengaplikasiannya dalam lingkungan sekitar ataupun kehidupan sehari-hari (Rahman \& Ningrum, 2017). Aspek yang dibahas pada mata kuliah fisika lingkungan di Universitas Jember yaitu matahari, air, angin, sampah serta teknologi energi alternatif dan terbarukan. Aspek sampah mengajarkan mahasiswa untuk memiliki kesadaran dalam pengelolaan sampah dan pemanfaatannya. Keberadaaan sampah plastik yang tidak terkendali dapat berdampak negatif bagi kehidupan makhluk hidup dan menyebabkan pencemaran lingkungan. Sehingga kesadaran mahasiswa dalam mengelola sampah plastik perlu ditumbuhkan.

Pencemaran lingkungan dapat diakibatkan karena keberadaan sampah plastik yang menumpuk. Kegiatan seharihari manusia tidak terlepas dari hal yang dapat menimbulkan sampah. Misalnya dalam pemakaian kantong plastik untuk mempermudah dalam membawa barang. Penggunaan kantong plastik secara terus menerus tanpa pengelolaan yang baik dapat menyebabkan penumpukan sampah dan mencemari lingkungan (Dwiyana Putra et al., 2021). Plastik dapat dimanfaatkan dalam berbagai kebutuhan hidup manusia, seperti bahan pembungkus makanan dan bahan baku otomotif. Terdapat banyak cara dalam mengolah plastik, karena plastik tergolong bahan yang dapat didaur ulang. Plastik termasuk jenis bahan kimia yang sulit terurai oleh alam, memerlukan waktu ratusan hingga ribuan tahun untuk memusnahkan plastik secara alami. Sehingga keberadaan sampah plastik sulit untuk dimusnahkan secara cepat dari muka bumi. Plastik dapat menyebabkan suhu udara menjadi meningkat karena sifat polimernya tidak berpori (Suminto, 2017).

Penggunaan plastik secara terus menerus yang dilakukan masyarakat dapat menjadikan adanya ketergantungan masyarakat terhadap plastik. Ketergantungan masyarakat terhadap plastik dapat memberikan dampak negatif bagi kesehatan manusia ataupun lingkungan. Rendahnya kesadaran masyarakat dalam penggunaan plastik menyebabkan keberadaan sampah plastik terus menumpuk (Wahyudin \& Afriansyah, n.d.). Menurut Deputi Pengendalian Pencemaran Negara Kementerian Lingkungan Hidup (KLH) tahun 2008, sampah plastik yang dihasilkan setiap individu dalam sehari sekitar $15 \%$ dari total $0,8 \mathrm{~kg}$ sampah yang dihasilkan. Dengan diasumsikan bahwa total penduduk Indonesia sekitar 220 juta penduduk, maka dalam sehari sampah plastik yang dihasilkan mencapai 26,500 ton. Jumlah sampah plastik yang dihasilkan di Indonesia mencapai 5,4 juta pertahun. Keberadaan sampah plastik mengalami peningkatan dan melebihi jumlah sampah kertas yang dihasilkan, dimana sampah kertas berjumlah 3,6 juta ton pertahun (Utami et al., n.d.).

Limbah plastik merupakan masalah serius yang menjadi penyebab pencemaran lingkungan. Karena plastik bersifat sulit terurai dengan alam, maka menyebabkan kesuburan tanah menurun. 


\section{Analisis Tingkat Kesadaran...Jupiter... Vol 2 No 1...Juli 2020...24-31}

Fitri Amelia, Sudarti

Penggunaan plastik oleh masyarakat sulit dikendalikan dan menyebabkan sampah plastik terus menumpuk. Pemerintah telah berupaya untuk dapat mengendalikan dampak negatif dari sampah plastik. Seperti menyediakan tempat sampah sesuai dengan jenis sampah (tempat sampah basah dan tempat sampah kering), namun upaya tersebut belum memperoleh hasil yang signifikan terhadap keberadaan sampah plastik. Banyak masyarakat yang membuang sampah tidak sesuai dengan jenis tempat sampahnya. Dibutuhkan suatu upaya efektif agar keberadaan sampah plastik dapat teratasi dengan baik dan tidak mengganggu lingkungan ataupun makhluk hidup. Pemanfaatan teknologi ataupun keterampilan dalam pengelolaan sampah plastik dapat menjadi alternatif sebagai upaya dalam mengatasi permasalahan sampah plastik. Namun, kesadaran masyarakat dalam penggunaan sampah plastik merupakan faktor penting yang dapat menjadi upaya mengurangi keberadaan sampah plastik. Kesadaran setiap individu terhadap bahayanya sampah plastik sekali pakai bagi lingkungan perlu ditumbuhkan (Rismayadi, 2017).

\section{BAHAN DAN METODE}

Penelitian ini menggunakan metode deskriptif yang pelaksanaannya melibatkan responden sebanyak 100 Mahasiswa semester 2 Pendidikan Fisika, Fakultas Keguruan dan Ilmu Pendidikan
Universitas Jember. Sugiyono (2009) mengemukakan bahwa metode deskriptif adalah salah satu metode penelitian yang memiliki tujuan untuk memberikan suatu gambaran sampel dari data yang diperoleh dan membuat kesimpulan yang dapat berlaku secara umum. Penelitian dilaksanakan pada bulan April 2021. Sumber data penelitian diperoleh dari kuisioner yang terdiri dari 10 pertanyaan dengan jenis pertanyaan berbentuk pilihan jawaban iya/tidak dan pilihan jawaban banyak. Pertanyaan kuisioner berkaitan dengan aspek pengetahuan responden mengenai pengelolaan sampah plastik dan kesadaran tindakan yang telah dilakukan responden dalam pengelolaan sampah plastik sekali pakai. Instrumen penelitian disusun dan dikembangkan sendiri oleh peneliti. Kuisioner dibagikan melalui link dalam bentuk google form dengan memanfaatkan group whatsapp. Data hasil kuisioner yang telah diperoleh kemudian dianalisis untuk mengetahui tingkat kesadaran mahasiswa terhadap penggunaan sampah plastik sekali pakai dengan melihat presentase jawaban yang dipilih responden.

\section{HASIL DAN PEMBAHASAN}

Hasil penelitian mengenai aspek pengetahuan dan aspek kesadaran tindakan mahasiswa pendidikan fisika semester 2 Universitas Jember terhadap pengelolaan sampah plastik sekali pakai dapat dilihat pada tabel 1 dan tabel 2 .

Tabel 1. Aspek Pengetahuan

\begin{tabular}{clc}
\hline No. & \multicolumn{1}{c}{ Aspek Pengetahuan } & Presentase \\
\hline 1. & Cara pengelolaan sampah plastik sekali pakai & $57 \%$ \\
2. & Istilah reuse, recycle and reduce (3R) & $96 \%$ \\
3. & Istilah diet sampah & $64 \%$ \\
\hline
\end{tabular}

Dari data hasil penelitian pada tabel 1 mengenai aspek pengetahuan diperoleh bahwa responden (Mahasiswa Pendidikan Fisika Semester 2 Universitas
Jember) telah banyak yang mengetahui cara pengelolaan sampah plastik sekali pakai dan istilah-istilah dalam pengelolaan sampah plastik. Dari hasil 
presentase terlihat bahwa terdapat responden yang tidak mengetahui cara pengelolaan sampah plastik sekali pakai, namun telah mengetahui istilah dalam pengelolaan sampah plastik.

Tabel 2. Aspek Kesadaran Tindakan

\begin{tabular}{llc}
\hline No. & \multicolumn{1}{c}{$\begin{array}{c}\text { Aspek Kesadaran } \\
\text { Tindakan }\end{array}$} & Presentase \\
\hline 1. & $\begin{array}{l}\text { Membuang sampah } \\
\text { plastik ditempatnya }\end{array}$ & $57 \%$ \\
2. & $\begin{array}{l}\text { Melakukan } \\
\text { pemilahan sampah }\end{array}$ & $96 \%$ \\
& $\begin{array}{l}\text { Meminimalisir } \\
\text { penggunaan sampah } \\
\text { plastik sekali pakai }\end{array}$ & $64 \%$ \\
& $\begin{array}{l}\text { Menerapkan reuse, } \\
\text { recycle and reduce } \\
\text { (3R) }\end{array}$ & $97 \%$ \\
5. & $\begin{array}{l}\text { Melakukan diet } \\
\text { sampah }\end{array}$ \\
\hline
\end{tabular}

Berdasarkan data pada tabel 2 mengenai aspek kesadaran tindakan diperoleh bahwa telah banyak Mahasiswa Pendidikan Fisika Semester 2 Universitas Jember yang memiliki kesadaran dalam melakukan upaya pengelolaan sampah plastik sekali pakai. Aspek kesadaran tindakan ini belum berupa tindakan nyata yang telah dilakukan responden dalam pengelolaan sampah plastik sekali pakai, sehingga dalam kuisioner terdapat jenis pertanyaan dengan jawaban banyak mengenai $3 \mathrm{R}$ dan diet sampah. Jenis pertanyaan tersebut ditujukan untuk mengetahui tindakan yang telah dilakukan oleh responden dalam upaya pengelolaan sampah plastik sekali pakai.

\section{Reduse, Reuse and Recycle (3R)}

Reuse, recycle and reduce (3R) merupakan salah satu cara untuk mengelola sampah plastik yang dilakukan dengan cara mengurangi (reduce), menggunakan kembali (reuse), dan mendaur ulang (recycle). Reduce berarti sikap yang dilakukan untuk meminimalisir timbulnya sampah, misalnya mengurangi pembelian produk yang berbahan plastik sekali pakai. Reuse dapat diartikan sebagai suatu cara dalam memanfaatkan kembali sampah tanpa memprosesnya lagi, misalnya memanfaatkan botol plastik untuk pot bunga. Recycle berarti mengolah kembali sampah menjadi produk lain yang bermanfat, misalnya mengubah sampah plastik menjadi kerajinan (Arisona, 2018). Berikut grafik hasil penelitian tingkat kesadaran tindakan Mahasiswa Pendidikan Fisika Semester 2 Universitas Jember dalam mengelola sampah plastik melalui upaya $3 \mathrm{R}$, 


\section{Analisis Tingkat Kesadaran...Jupiter... Vol 2 No 1...Juli 2020...24-31}

Fitri Amelia, Sudarti

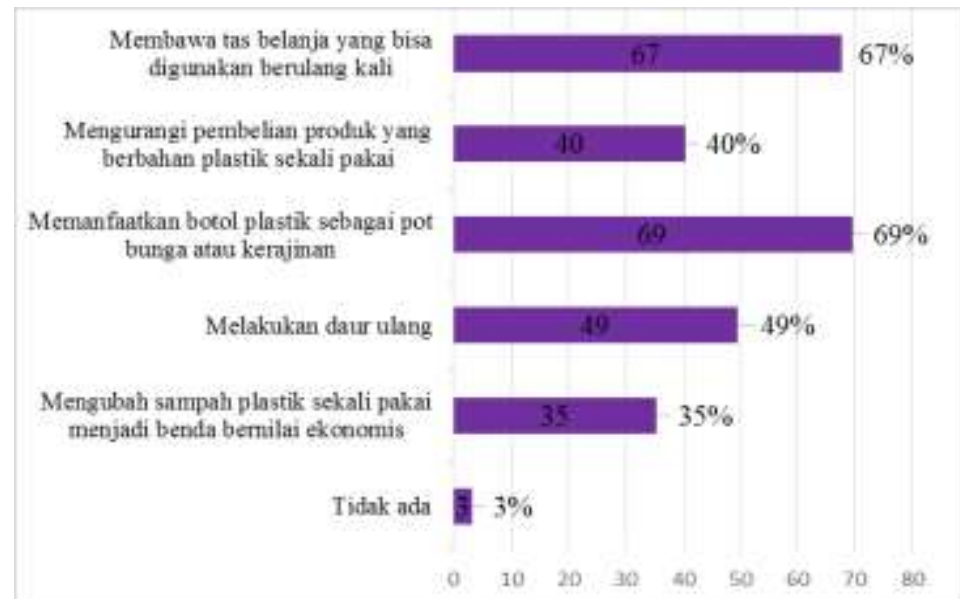

Gambar 1. Grafik presentase tingkat kesadaran tindakan responden dalam mengelola sampah plastik melalui upaya $3 \mathrm{R}$

Dari data hasil penelitian pada gambar 1 diperoleh bahwa banyak responden yang telah menerapkan upaya 3R dalam mengelola sampah plastik sekali pakai, hanya $3 \%$ responden yang tidak menerapkan upaya 3R. Tindakan yang banyak dilakukan responden berkaitan dengan reuse yaitu memanfaatkan botol plastik sebagai pot bunga atau kerajinan dengan presentase $69 \%$. Upaya 3R lain yang telah diterapkan Mahasiswa Pendidikan Fisika Semester 2 Universitas Jember yaitu membawa tas yang bisa digunakan berulang kali, mengurangi pembelian produk yang berbahan plastik sekali pakai, melakukan daur ulang dan mengubah sampah plastik sekali pakai menjadi benda bernilai ekonomis. Presentase dari banyaknya mahasiswa yang telah menerapkan upaya 3R tersebut berturut-turut adalah $67 \%, 40 \%, 49 \%$ dan $35 \%$. Sehingga hanya sedikit mahasiswa yang memiliki kesadaran untuk mengubah sampah plastik sekali pakai menjadi benda bernilai ekonomis.

\section{Diet Sampah}

Diet sampah merupakan segala upaya yang dilakukan untuk meminimalisir timbulnya sampah, dapat dilakukan dengan menggunakan atau memilah barang yang akan dibuang menjadi sampah. Diet sampah plastik sekali pakai berarti upaya dalam meminimalisir penggunaan plastik sekali pakai, misalnya mengganti plastik dengan bahan lain yang ramah lingkungan (kantong plastik diganti tas kain) (Izzati \& Safitri, 2019). Mahasiswa Pendidikan Fisika Semester 2 Universitas Jember telah berupaya menerapkan diet sampah plastik sekali pakai dalam kehidupan sehari-harinya, berikut grafik hasil penelitian banyaknya mahasiswa yang telah menerapkan tindakan diet sampah, 


\section{Analisis Tingkat Kesadaran...Jupiter... Vol 2 No 1...Juli 2020...24-31}

Fitri Amelia, Sudarti

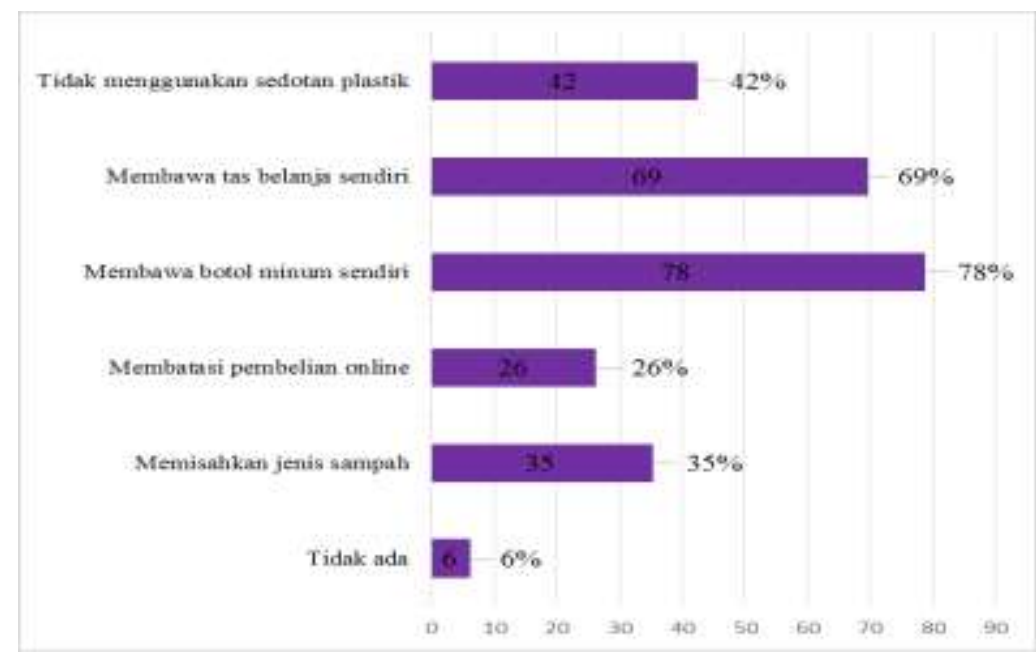

Gambar 2. Grafik presentase tingkat kesadaran tindakan responden dalam menerapkan upaya diet sampah

Berdasarkan data hasil penelitian pada gambar 2 diperoleh bahwa terdapat $6 \%$ responden yang tidak memiliki kesadaran untuk menerapkan diet sampah plastik sekali pakai dalam kehidupan sehari-harinya. Mahasiswa Pendidikan Fisika Semester 2 Universitas Jember lebih banyak menerapkan upaya diet sampah dengan membawa botol minum sendiri, presentase banyaknya mahasiswa yang menerapkan upaya tersebut adalah $78 \%$. Upaya diet sampah plastik dapat dilakukan dengan membatasi pembelian online, karena barang yang dibeli online biasanya menggunakan kemasan plastik sekali pakai. Dari diagram hasil penelitian hanya 26\% Mahasiswa Pendidikan Fisika Semester 2 Universitas Jember yang memiliki kesadaran untuk membatasi pembelian online sebagai upaya diet sampah plastik sekali pakai. Upaya diet sampah lainnya yang telah diterapkan Mahasiswa Pendidikan Fisika Semester 2 Universitas Jember yaitu tidak menggunakan sedotan plastik, membawa tas belanja sendiri, dan memisahkan jenis sampah. Presentase banyaknya mahasiswa yang memiliki kesadaran untuk menerapkan upaya diet sampah tersebut yaitu tidak menggunakan sedotan plastik sebesar $42 \%$, membawa tas belanja sendiri $69 \%$ dan memisahkan jenis sampah sebesar $35 \%$.

\section{KESIMPULAN}

Berdasarkan hasil analisis diatas dapat disimpulkan bahwa tingkat kesadaran Mahasiswa Pendidikan Fisika Semester 2 Universitas Jember terhadap pengelolaan sampah pastik sekali pakai sudah baik dilihat dari aspek pengetahuan dan aspek kesadaran tindakan. Hal tersebut terbukti dari banyaknya presentase yang diperoleh pada setiap pertanyaan dalam kuisioner, serta terbukti hanya $3 \%$ responden yang tidak melakukan upaya 3R dan $6 \%$ responden tidak melakukan upaya diet sampah.

\section{DAFTAR PUSTAKA}

Arisona, R. D. (2018). Pengelolaan Sampah 3R (Reduce, Reuse, Recycle) pada Pembelajaran IPS untuk Menumbuhkan Karakter Peduli Lingkungan. Jurnal Pendidikan Islam, 3(1), 42.

Dwiyana Putra, I. M. O., Sugiartha, I. N. G., \& Suryani, L. P. (2021). Pengelolaan Sampah Plastik Rumah Tangga dalam Rangka Pencegahan Pencemaran Lingkungan (Study di 


\section{Analisis Tingkat Kesadaran...Jupiter... Vol 2 No 1...Juli 2020...24-31}

Fitri Amelia, Sudarti

Lingkungan Kelurahan Pedungan Kecamatan Denpasar Selatan Kota Denpasar). Jurnal Konstruksi Hukum, 2(1),

86-91. https://doi.org/10.22225/jkh.2.1.2974. 86-91

Izzati, F., \& Safitri, M. N. (2019). Pemberdayaan Perempuan Melalui Program Diet Kantong Plastik. Bina' Al-Ummah, 14(2), 119-136. https://doi.org/10.24042/bu.v14i2.562 8

Rahman, M. H., \& Ningrum, R. W. (2017). Penggunaan Project Based Learning Untuk Meningkatkan Kepedulian Lingkungan. 8(1), 12.

Rismayadi, B. (2017). Penyuluhan Kesadaran Masyarakat Seputar Kampus Universitas Buana Perjuangan Karawang Mengenai Dampak Sampah serta Pelatihan Pemanfaatan Sampah Plastik untuk Kegiatan Ekonomi Kreatif. Buana Ilmu, 1(2). https://doi.org/10.36805/bi.v1i2.418

Siswadi, S., Taruna, T., \& Purnaweni, H. (2012). Kearifan Lokal Dalam Melestarikan Mata Air (Studi Kasus di Desa Purwogondo, Kecamatan Boja, Kabupaten Kendal). Jurnal Ilmu Lingkungan, $\quad 9(2), \quad 63$. https://doi.org/10.14710/jil.9.2.63-68

Suminto, S. (2017). Ecobrick: Solusi cerdas dan kreatif untuk mengatasi sampah plastik. PRODUCTUM Jurnal Desain Produk (Pengetahuan dan Perancangan Produk), 3(1), 26. https://doi.org/10.24821/productum.v3 i1.1735

Utami, R. N., Wahyuningsih, T., \& Purwaningtyas, A. (n.d.). Kesadaran Penggunaan Plastik Sekali Pakai Mahasiswa Pendidikan Biologi Universitas Tidar. 5.
Wahyudin, G. D., \& Afriansyah, A. (n.d.). Penanggulangan Pencemaran Sampah Plastik Di Laut Berdasarkan Hukum Internasional. 22. 